\title{
Correction: Fungal Alkaloid Occurrence in Endophyte-Infected Perennial Ryegrass during Seedling Establishment
}

\author{
Katrin G. Hewitt ${ }^{1,6} \cdot$ Wade J. Mace ${ }^{2} \cdot$ Catherine M. McKenzie $^{3} \cdot$ Cory Matthew $^{4} \cdot$ Alison J. Popay $^{5}$
}

Published online: 27 March 2020

(C) Springer Science+Business Media, LLC, part of Springer Nature 2020

\section{Correction: Journal of Chemical Ecology https://doi.org/10.1007/s10886-020-01162-w}

The original version of this article unfortunately contained a mistake. There is a mistake in the affiliation section and Figure 6 . The correct affiliation and Figure 6 are shown here.

The original article has been corrected.

The online version of the original article can be found at https://doi.org/ 10.1007/s10886-020-01162-w

Katrin G. Hewitt

katrin_ruppert@web.de

Wade J. Mace

wade.mace@agresearch.co.nz

Catherine M. McKenzie

Catherine.McKenzie@plantandfood.co.nz

Cory Matthew

C.Matthew@massey.ac.nz

Alison J. Popay

alison.popay@agresearch.co.nz
1 Present address: The New Zealand Institute for Plant and Food Research Limited (Plant \& Food Research), Physiological Chemistry, Ruakura, Private Bag 3230, Waikato Mail Centre, Hamilton 3240, New Zealand

2 AgResearch Ltd, Forage Improvement, Grasslands Research Centre, Private Bag 11008, Palmerston North 4442, New Zealand

3 Plant \& Food Research, Data Science, 412 No 1 Road, RD 2, Te Puke 3182, New Zealand

4 School of Agriculture and Environment, Massey University, Private Bag 11-222, Palmerston North 4442, New Zealand

5 AgResearch Ltd, Biocontrol \& Biosecurity, Ruakura Research Private Bag 3123, Hamilton 3240, New Zealand

6 AgResearch Ltd, Biocontrol \& Biosecurity, Grasslands Research Centre, Private Bag 11008, Palmerston North 4442, New Zealand 


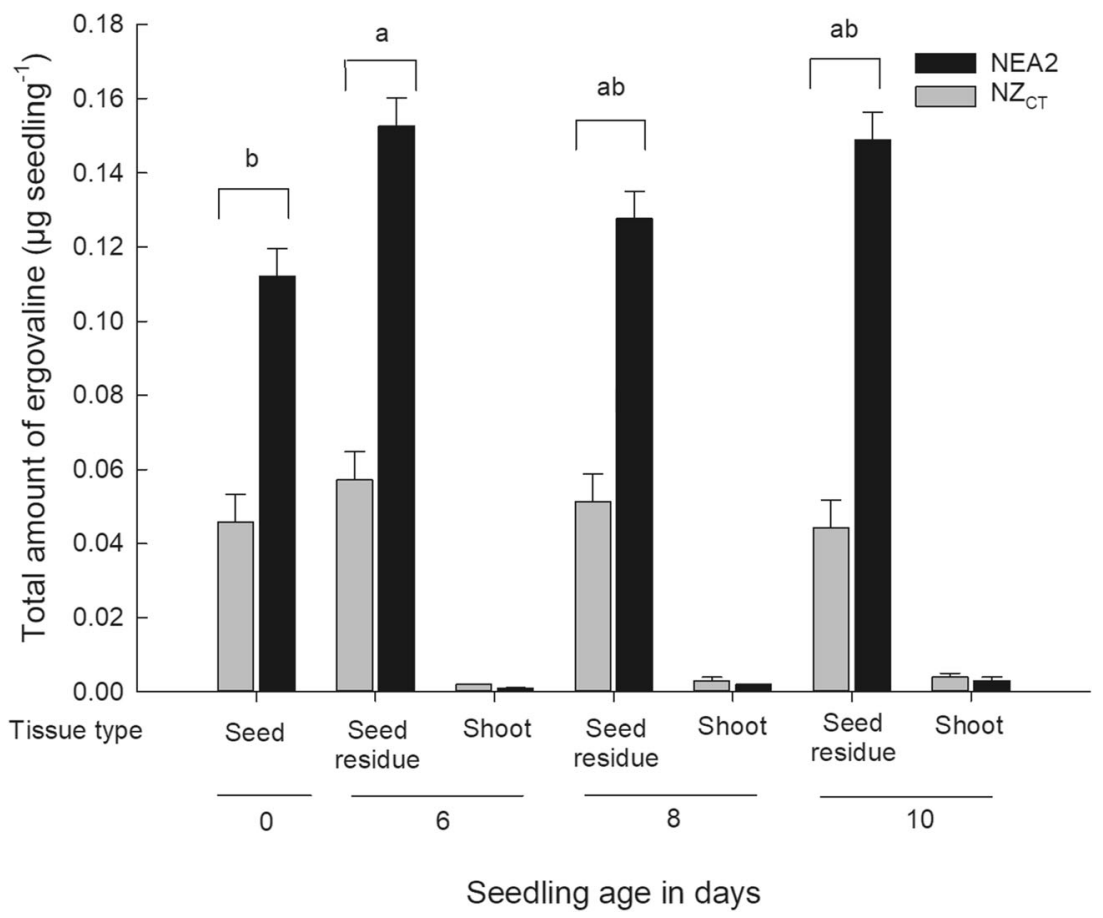

Fig. 6 Total amount of ergovaline $\left(\mu \mathrm{g}\right.$ seedling $\left.{ }^{-1}\right)$ of seedlings infected with Epichloë festucae var. lolii strains NEA2, and NZ measured in seeds, seed residues, and during the early establishment phase. Error bars represent standard errors of the mean $(+1$ $\mathrm{SEM})$. Values with the same letter are not significantly different at $\alpha<0.05$ (Bonferroni Correction test) 